\title{
Letter to the editor on the article of 'Effects of dutasteride on sex hormones and cerebrospinal steroids in patients treated for benign prostatic hyperplasia'
}

\author{
Yuan-Ping $\mathrm{Xu}^{1} \cdot$ Peng Zhang ${ }^{2}$ \\ Received: 11 May 2021 / Accepted: 24 June 2021 / Published online: 6 July 2021 \\ (c) The Author(s), under exclusive licence to Springer Science+Business Media, LLC, part of Springer Nature 2021
}

We read a recently published article entitled 'Effects of dutasteride on sex hormones and cerebrospinal steroids in patients treated for benign prostatic hyperplasia' in the journal of Endocrine [1]. The authors compared two groups of BPH patients with prostate volume $\leq 40 \mathrm{~mL}$ (group A) and prostate volume $>40 \mathrm{ml}$ (group B) pre-scheduled for surgery treatment. Dutasteride was treated in the patients with prostate volume $>40 \mathrm{ml}$ for at least 6 months before surgery. They did the measurement of serum sex steroids and gonadotropin levels, in addition with the neuroactive steroid levels in the cerebrospinal fluid. The authors found that total testosterone (TT) and $17 \beta$-estradiol $\left(\mathrm{E}_{2}\right)$ was increased, while PSA was decreased in the serum of Group $B$ with the treatment of dutasteride. As we know, PSA is positively associated with androgen and prostate volume in the BPH patients and the PSA may decrease in the BPH patients of dutasteride treatment with larger prostate volume [2]. It is possible that dutasteride can inhibit testosterone transforming to dihydrotestosterone (DHT) resulting in decreased DHT levels as a result of decreased PSA levels in Group B. DHT as the most active androgen may have more biological activity in the human body than TT. However, the author did not analyse serum DHT and discuss the reason of decreased PSA levels along with increasded TT levels in the Group B with lagrer prostate volume.

\section{Compliance with ethical standards}

Conflict of interest The authors declare no competing interests.

Publisher's note Springer Nature remains neutral with regard to jurisdictional claims in published maps and institutional affiliations.

\section{References}

1. V. Favilla, R. Cannarella, F. Trovato, G.L. Volti, A. Distefano, E. Grimaldi, G. La Camera, S. La Vignera, R.A. Condorelli, A. E. Calogero, S. Cimino: Effects of dutasteride on sex hormones and cerebrospinal steroids in patients treated for benign prostatic hyperplasia. Endocrine (2021). https://doi.org/10.1007/s12020021-02675-4

2. P. Zhang, W.L. Hu, B. Cheng, Y.J. Zeng, X.H. Wang, T.Z. Liu, W. B. Zhang, Which play a more important role in the development of large-sized prostates $(>/=80 \mathrm{ml})$, androgen receptors or oestrogen receptors? A comparative study. Int. Urol. Nephrol. 48(3), 325-333 (2016)

Peng Zhang

monkeyzhangpeng@163.com

1 Department of Gynecology, Wuhan Third Hospital, Tongren Hospital of Wuhan University, 430071 Wuhan, China

2 Department of Urology, Wuhan Third Hospital, Tongren Hospital of Wuhan University, 430071 Wuhan, China 